\title{
Latest News \& Updates from the Personalized Medicine Coalition
}

\section{Letter from the Executive Director}

The election of Barack Obama as President of the USA presents an unprecedented, perhaps not-to-be-repeated opportunity to advance the agenda for personalized medicine, change the way medicine is practiced and improve healthcare.

President-elect Obama wrote the first bill in Congress that identified the promise of personalized medicine. Among other things, his bill created incentives to encourage the co-development of diagnostic and therapeutic products, called for funding to train a new workforce in genetics and genomics, established a biobanking database and authorized an interagency workgroup to coordinate the government's policies so that they promote the new paradigm.

As president, his horizon is much broader, but his interest in personalized medicine is likely to increase. He faces the central conundrum of healthcare: extend coverage to the $15 \%$ of the American public who do not have health insurance, spur the future research and development upon which patients depend and, at the same time, cut systemic, exploding costs that reduce productivity in the economy.

Unless President-elect Obama can simultaneously achieve these three competing goals, his healthcare plan is likely to face serious opposition. Americans, historically a "people of plenty", as the sociologist David Potter wrote 50 years ago, are nearly certain to reject any plan to which the label 'rationing' can be applied. Indeed, a plan that does not promise improved overall quality of care, offer an expectation that new discoveries will lead to better medicine tomorrow and lower systemic costs is unlikely to garner sufficient public support to be enacted.

The only way to square the circle of increasing the quality and supply of healthcare while simultaneously cutting costs is to deploy new technologies and new approaches that introduce efficiencies in the system, while also emphasizing prevention, which will keep people healthier and also reduce the costs of chronic care. This is why during the recent presidential campaign, building on Health and Human Services Secretary Michael Leavitt's generally unfunded initiative, President-elect Obama (and presidential candidate Senator John McCain) supported investing in health information technologies. Since the election, President-elect Obama has floated the idea of including US $\$ 10$ billion in a stimulus package for health information technologies that could help build an infrastructure for more rational decision-making in medicine.

One reason I believe that President-elect Obama did not focus on personalized medicine during the campaign, with the exception of a reference to it in his "plan to combat cancer", was because the relatively new concept requires a review of complex biomedical issues that do not lend themselves to the exigencies of modern politics. In addition, although the Personalized Medicine Coalition estimates that there are almost 40 personalized medicine products on the market today, we have not yet reached a tipping point when physicians, payers, and particularly patients demand a diagnostic test before therapy is prescribed.

This is why the Personalized Medicine Coalition contends that our proposed agenda of increasing investment in translational research, creating a friendlier regulatory environment that facilitates the co-development of diagnostic and therapeutic products, and putting in place a reimbursement system that supports personalized medicine products is all the more compelling.

We know, moreover, that without more examples of widely used drug-diagnostic products, risk-adverse skeptics will not support reconstructing health systems around

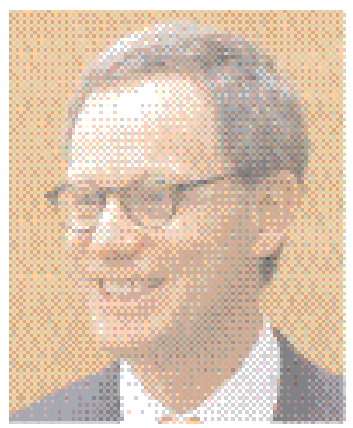

\section{Edward Abrahams}

Personalized Medicine Coalition,

1225 New York Avenue, NW, Suite 400,

Washington, DC 20005 USA

Tel.: +1 2025891770

Fax: +1 2025891778

eabrahams@

personalizedmedicinecoalition.org

\section{"Since the election, President-elect Obama has floated the idea of including US\$10 billion in a stimulus package for health information technologies that could help build an infrastructure for more rational decision-making in medicine."}


"The principles of personalized medicine ... are the only way Obama's health plan can achieve everything the American public wants." the world along these lines. We therefore also propose that clinical trails designed to determine if personalized approaches to care can produce both better patient outcomes and reduced costs be conducted sooner rather later.

In brief, the principles of personalized medicine, including getting the treatment right the first time and preventing illness when possible, are the only way Obama's health plan can achieve everything the American public wants.

\section{Edward Abrahams, Executive Director,} Personalized Medicine Coalition 